\title{
MODELLING THE MATERIAL PROPERTIES AND BEHAVIOUR OF Ni-BASED SUPERALLOYS
}

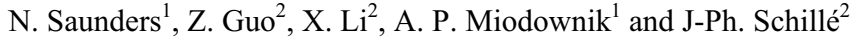 \\ ${ }^{1}$ Thermotech Ltd., Surrey Technology Centre, The Surrey Research Park, Guildford GU2 7YG, U.K. \\ ${ }^{2}$ Sente Software Ltd., Surrey Technology Centre, The Surrey Research Park, Guildford GU2 7YG, U.K.
}

Keywords: Physical Properties, Solidification, Mechanical Properties, High Temperature Properties, Creep, TTT/CCT diagrams

\begin{abstract}
At the last two Superalloy meetings at Seven Springs, work on the development of thermodynamic modelling tools for application to multi-component Ni-based superalloys has been presented. Such modelling has become quite widespread, providing significant benefit. However, its applicability often falls short from directly providing the information that is actually required and, by itself, cannot be directly used to model properties being targeted by the end user, e.g. TTT/CCT diagrams, mechanical properties, thermophysical and physical properties. To overcome these limitations a new computer programme has been developed, called JMatPro, an acronym for Java-based Materials Properties software. The properties which can be calculated are wide ranging, including thermo-physical and physical properties (from room temperature to the liquid state), TTT/CCT diagrams, stress/strain diagrams, proof and tensile stress, hardness, coarsening of $\gamma^{\prime}$ and $\gamma^{\prime \prime}$ and creep.
\end{abstract}

\section{Introduction}

Thermodynamic modelling tools [1] are becoming increasingly used for Ni-based superalloys $[2,3,4,5,6,7,8,9]$. In themselves, such tools provide significant benefit. However, their applicability often falls short from directly providing the information that is actually required. For example, thermodynamic modelling helps towards the understanding of changes in phase constitution of a material as a function of composition or temperature. However, there is then a gap in translating this information into the properties being targeted by the end user, e.g. TTT/CCT diagrams, mechanical properties, thermo-physical and physical properties.

To overcome these limitations a new computer programme has been developed $[10,11]$ called JMatPro, an acronym for Javabased Materials Properties software. The properties which can be calculated are wide ranging, including thermo-physical and physical properties (from room temperature to the liquid state), TTT/CCT diagrams, stress/strain diagrams, proof and tensile stress, hardness, coarsening of $\gamma^{\prime}$ and $\gamma^{\prime \prime}$ and creep.

A feature of the new programme is that the calculations are based, as far as possible, on sound physical principles rather than purely statistical methods. Thus many of the shortcomings of methods such as regression analysis can be overcome. It allows sensitivity to microstructure to be included for many of the properties and also means that the true inter-relationship between properties can be developed, for example in the modelling of creep and precipitation hardening. The purpose of the present paper is to describe the technical background behind the new programme, giving extensive examples of its application and validation for multi-component commercial alloys.

\section{Applications}

Thermo-physical and Physical Properties

In the Solid State.

Thermo-physical and physical properties are an important part of materials science, particularly at the present time when such data is a critical input for software programmes dealing with process modelling. A major achievement of the JMatPro software project has been the development of an extensive database for the calculation of physical properties that can be linked to its thermodynamic calculation capability. For individual phases in multi-component systems, properties, such as molar volume, thermal conductivity, Young's modulus, Poisson's ratio, etc., are calculated using simple pair-wise mixture models, similar to those used to model thermodynamic excess functions in multicomponent alloys.

$$
P=\sum_{i} x_{i} P_{i}^{o}+\sum_{i} \sum_{j>i} x_{i} x_{j} \sum_{v} \Omega_{i j}^{v}\left(x_{i}-x_{j}\right)^{v}
$$

where, $P$ is the property of the phase, $P_{i}^{o}$ is the property of the phase in the pure element, $\Omega_{i j}^{v}$ is a binary interaction parameter dependent on the value of $v, x_{i}$ and $x_{j}$ are the mole fractions of elements $i$ and $j$ in the phase. Both $P_{i}^{o}$ and $\Omega_{i j}^{v}$ are temperature dependent. It is possible to include ternary or higher order effects where appropriate.

Once the property of the individual phase is defined, the property of the final alloy can be calculated using mixture models that can account for the effect of microstructure on the final property [12,13]. Such models, which were developed for 2-phase systems, have been extended to allow calculations to be made for multi-phase structures [14].

Utilising well established relationships between certain properties, (e.g. thermal and electrical conductivity), allows other properties to be calculated without using further databases, so that the following properties can be modelled - volume, density, expansion coefficient, Young's, bulk and shear moduli, Poisson's ratio, thermal conductivity and diffusivity, electrical conductivity and resistivity, viscosity and diffusivity of the liquid. Furthermore, it is possible to calculate lattice parameters for the $\gamma$ and $\gamma^{\prime}$ phases in Ni-based superalloys and calculate $\gamma / \gamma^{\prime}$ mismatch as a function of temperature. 


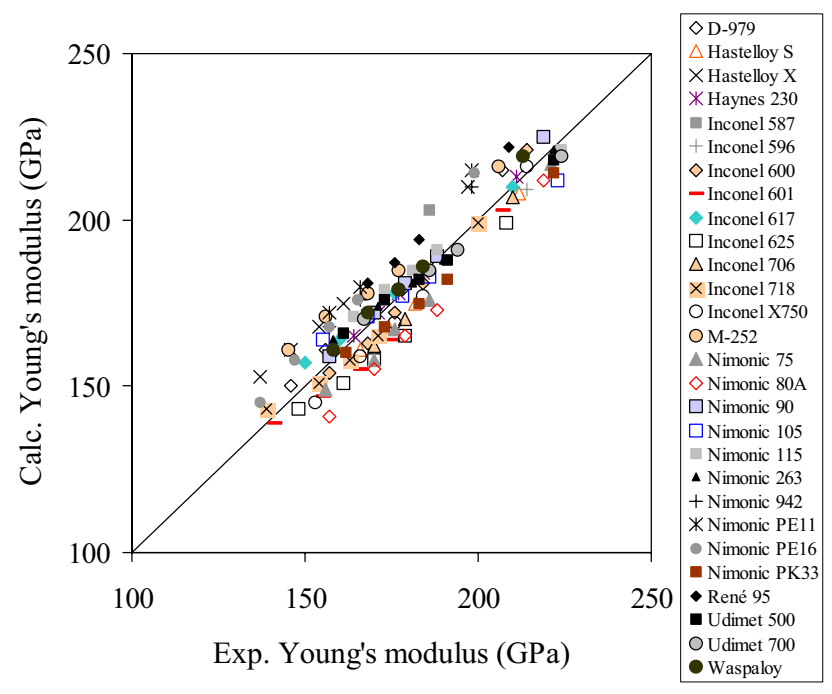

Figure 1. Comparison between experimental [15] and calculated Young's modulus for various disk alloys.

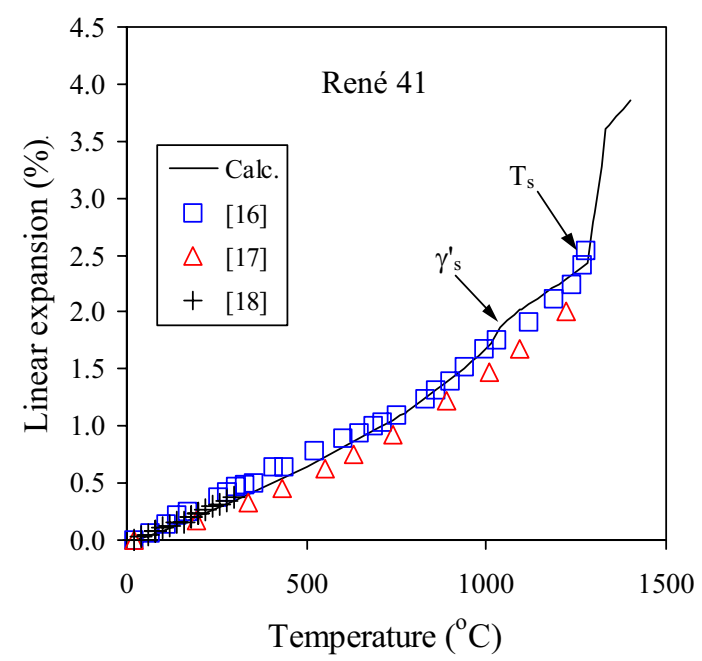

Figure 2. Comparison between experimental $[16,17,18]$ and calculated linear expansion for a René 41 alloy

Figure 1 compares experimental [15] and calculated Young's modulus for various wrought alloys between room temperature (RT) and $870^{\circ} \mathrm{C}$, while Figure 2 shows a comparison between calculated and experimentally measured [16,17,18] linear expansion for a René $41 \mathrm{Ni}$-based superalloy. For $\gamma$ alloys such as the Hastelloy types, the phase constitution changes little, if at all, in the temperature range of interest However for $\gamma / \gamma^{\prime}$ alloys this assumption cannot be made. The calculations have therefore been made assuming that the phases present below the final heat treatment temperature (FHTT) are those calculated at the FHTT and kinetically "frozen in". Above the FHTT, the phases are allowed to equilibriate, which leads to, for example, the dissolution of $\gamma^{\prime}$. This approach provides excellent results and is consistent with a simple $\sqrt{D t}$ calculation that suggests that temperatures between $750-850^{\circ} \mathrm{C}$ (where most $\gamma / \gamma^{\prime}$ wrought alloys are heat treated) diffusion distances would become comparable to that of $\gamma^{\prime}$ particle spacings.

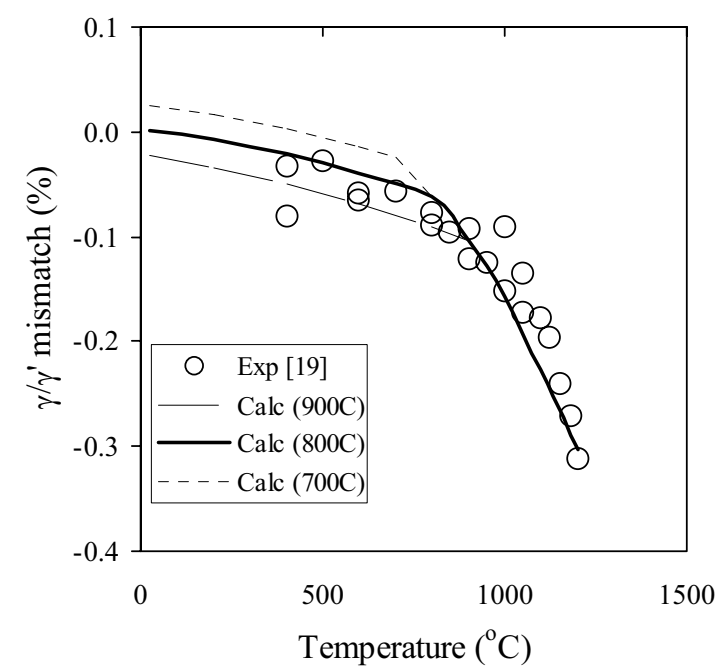

Figure 3. Comparison between experimental [19] and calculated $\gamma / \gamma^{\prime}$ mismatch for an AM1 single crystal alloy.

The effect of changes in phase constitution are apparent for the René 41 alloy (Fig.2). Below $760^{\circ} \mathrm{C}$, the FHTT for this alloy, the linear expansion is fairly linear, but deviates quite markedly from linear above the FHTT as the amount of $\gamma$ and $\gamma^{\prime}$ changes. The $\gamma^{\prime}$ solvus $\left(\gamma_{\mathrm{s}}^{\prime}\right)$ is clearly visible as is the solidus $\left(\mathrm{T}_{\mathrm{s}}\right)$.

Because the property databases hold information for each phase it is possible to calculate the $\gamma / \gamma^{\prime}$ mismatch as a function of temperature. Figure 3 shows a comparison between experimentally measured [19] and calculated $\gamma / \gamma^{\prime}$ mismatch for the single crystal alloy AM1. In the experiment the alloy would have been held for some time at the various temperatures. We have calculated $\gamma / \gamma^{\prime}$ mismatch assuming the $\gamma / \gamma^{\prime}$ structure is kinetically "frozen in" below $700^{\circ}, 800^{\circ}$ and $900^{\circ} \mathrm{C}$ respectively. The FHTT was $870^{\circ} \mathrm{C}$. It can clearly be seen that there are two regimes of behaviour. Below about $850^{\circ} \mathrm{C}$ where the $\gamma / \gamma^{\prime}$ mismatch is governed purely by the difference in expansion coefficient between the kinetically "frozen in" $\gamma / \gamma$ ' structure and above $850^{\circ} \mathrm{C}$ where the $\gamma / \gamma^{\prime}$ structure changes and $\gamma$ and $\gamma^{\prime}$ compositions approach their equilibrium values. In particular the $\gamma$ composition changes markedly as $\gamma^{\prime}$ stabilising elements, such as $\mathrm{Al}, \mathrm{Ta}$ and $\mathrm{Ti}$, are taken back into solution in $\gamma$.

\section{During Solidification}

The thermo-physical and physical properties of the liquid and solid phases are critical components in casting simulations. Such properties include the fraction solid transformed, enthalpy release, thermal conductivity, volume and density, all as a function of temperature. However, due to the difficulty in experimentally determining such properties at solidification temperatures, little information exists for multi-component alloys. The calculation of physical properties has therefore been extended to include their calculation for solidification.

Recently the application of so-called "Scheil-Gulliver" (SG) modelling via a thermodynamic modelling route has led to the ability to predict a number of critical thermophysical properties for alloys such as Ni-based superalloys [2,20,21]. Such calculations can be computationally very fast and readily used within solidification packages. The model assumes that solute 
diffusion in the solid phase is slow enough to be considered negligible and that diffusion in the liquid is fast enough to assume that diffusion is complete. Such a process is quite simple to model using thermodynamic calculations based on the CALPHAD method and has been described in a numerous publications $[2,6,20]$. It is known that some back diffusion will occur, but for many alloy types, including most Ni-based superalloys. the SG assumption leads to good results for much of the solidification range and can be used to obtain high quality input for casting simulations $[2,6,9,20]$.

The physical properties of the liquid phase has been extensively modelled and results presented for many types of alloy in previous work $[22,23,24,25,26]$. These can be combined with ScheilGulliver based calculations and physical properties for the solid state to provide soundly based changes in physical properties during the casting process.

An example of volume change during solidification between $1400^{\circ} \mathrm{C}$ and $1200^{\circ} \mathrm{C}$ is shown in Figure 4 for a Mar M246 alloy. The volume can be calculated all the way to room temperature (RT) if required. and used in combination with modulus calculations to calculate residual stresses in the casting.

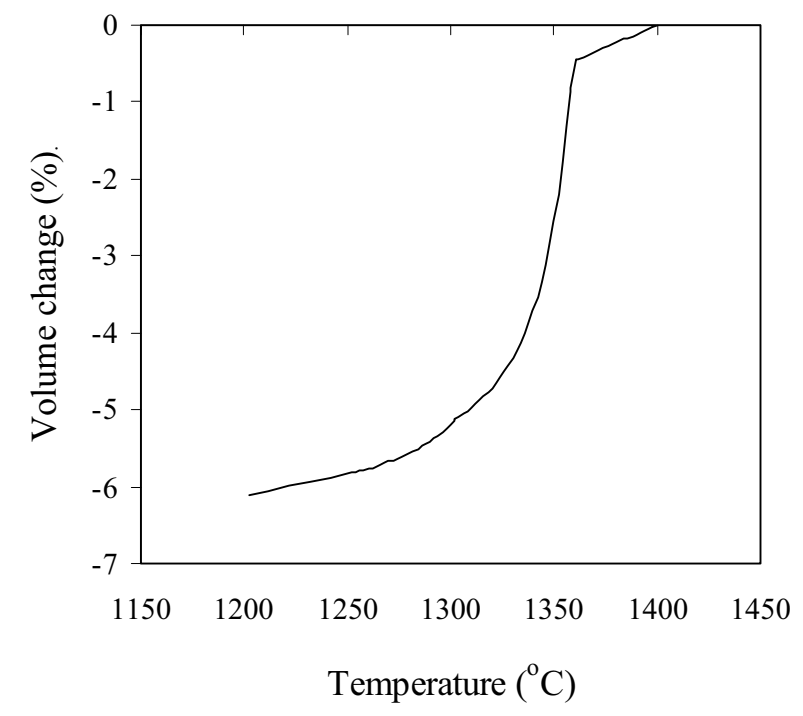

Figure 4. Calculated volume change during casting of a Mar M246 alloy.

Fine detail can be obtained, for example the density of the liquid in the mushy zone (Figure 5), which can be utilised for the calculation of casting defects and, potentially, macrosegregation in ingot casting and re-melting processes. In this case we have shown the varying behaviour of liquid phase in the mushy zone for 3 superalloys, showing the quite different behaviour of alloy 706 , which shows signs of a density inversion, in comparison to 718 and 625. Such behaviour is consistent with observations of defects in these alloys and various calculations of liquid density of Auburtin et al. [27].

In terms of calculation of the Rayleigh number and its application to defect formation it is also important to obtain liquid viscosities in the mushy zone. Figure 6 shows the calculated liquid viscosity in two alloys, 713 and 718, during solidification. Experimental measurements of the fully liquid alloys are shown for

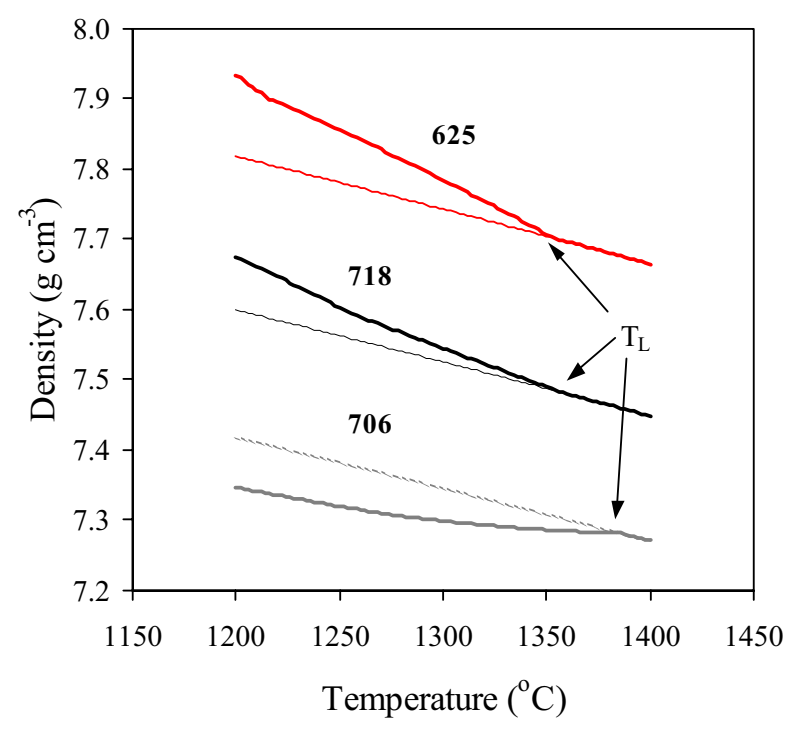

Figure 5. Calculated densities of the liquid phase during solidification of 625, 718 and 706 alloys (bold lines).

Fine lines show the density of the liquid alloys extrapolated from high temperature $\left(\mathrm{T}_{\mathrm{L}}\right.$ is the liquidus).

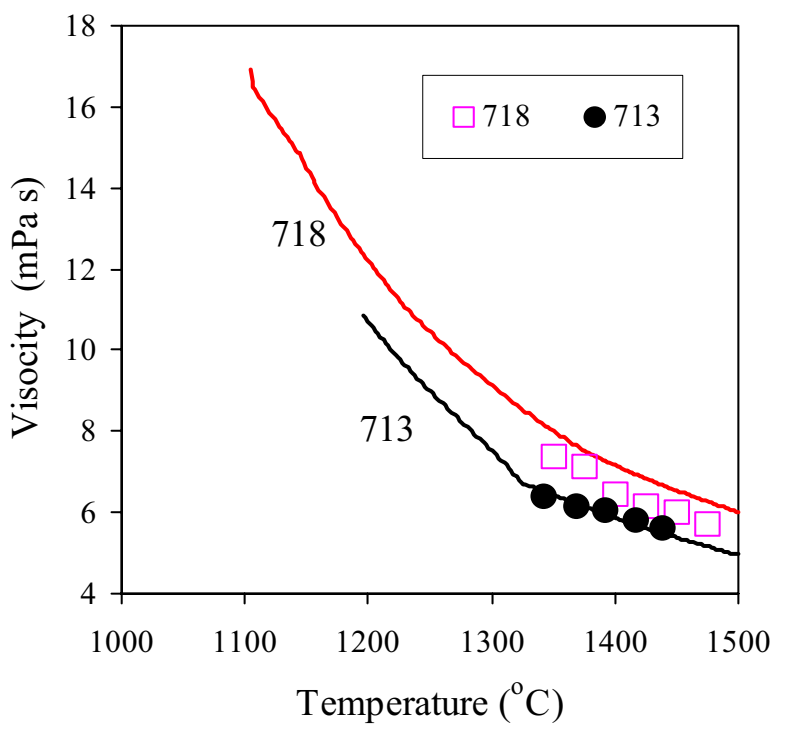

Figure 6. Calculated viscosity of the liquid during solidification of alloys 713 and 718. Experimental data for the fully liquid state [28] shown for comparison.

comparison [28]. It can be seen that a simple extrapolation of the high temperature liquid properties into the mushy zone will seriously underestimate the viscosity for both alloys.

In all cases of solidification, the properties of the liquid in the mushy zone are sensitive to partitioning of the various elements of the alloy. By combining the thermodynamic calculation with the physical property calculation it is now possible to explicitly consider the effect of changing liquid composition on a wide variety of physical properties. Such a capability will provide substantial benefit for solidification modellers in the analysis and prediction of defects during casting. 

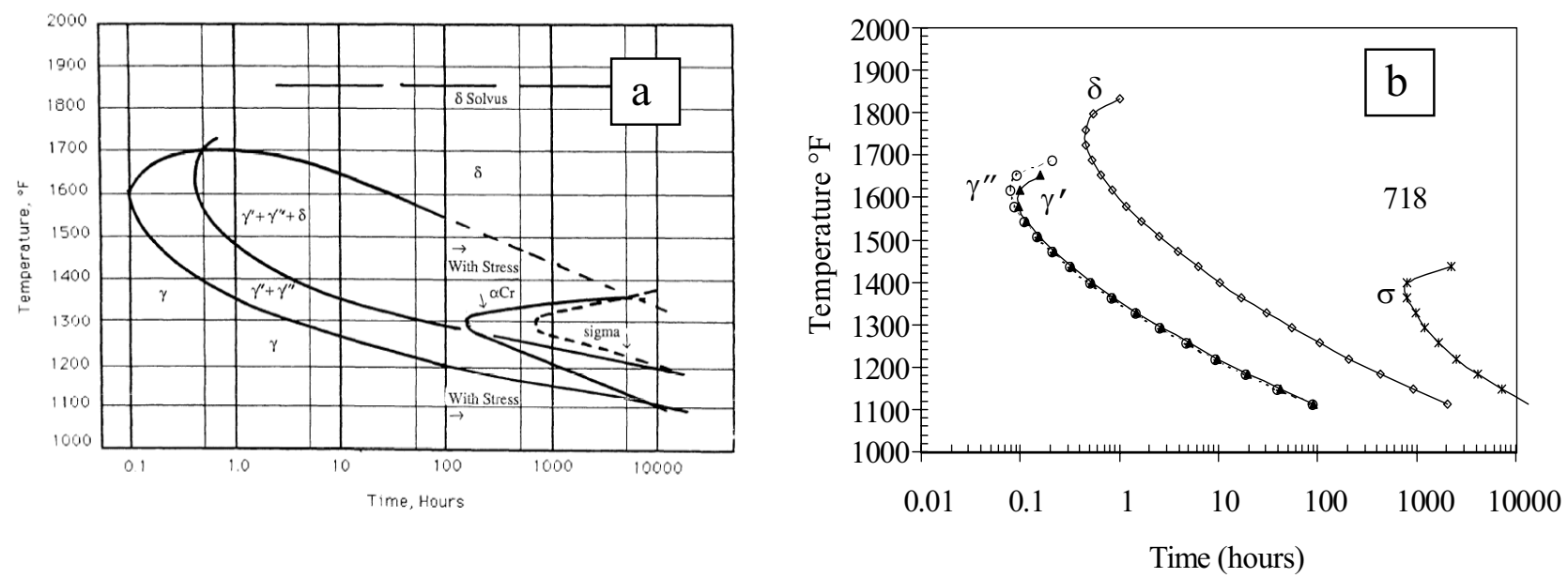

Figure 7. (a) Experimentally observed [30] and calculated [10] TTT diagram for alloy 718.

\section{$\underline{\text { TTT and CCT Diagrams }}$}

In previous papers an approach for the calculation of isothermal Time-Temperature-Transformation (TTT) and Continuous Cooling Transformation (CCT) diagrams has been described $[10,11,26,29]$; details of the scientific method are provided in ref.29. The kinetic treatment is based on a modified JohnsonMehl-Avrami model where critical input, such as driving forces, compositions of the precipitating phases, etc. are obtained from thermodynamic calculations. Work has been undertaken to create the requisite diffusion database for Ni-alloys, assess the typical nucleation and shape characteristics for the various types of precipitate, and validate the approach against experiment.

An advantage of the current modelling method is that few input parameters need to be empirically evaluated. Where empirical values are used, for example in consideration of shape and nucleant density, specific values have been defined for the various precipitates. Once these values are defined, they have then been self-consistently applied and the model is therefore used in a predictive fashion. Results of calculated start of transformation for various alloys are shown in Figures 7-10. In all cases start of transformation has been taken as 0.5 mole $\%$ phase formed.

Figure 7 shows the calculated TTT diagram [10] for a 718 alloy and compares it with experiment [30]. In this case the $\gamma^{\prime}, \gamma^{\prime \prime}$ and $\delta$ phases are considered to form from supersaturated $\gamma$, quenched from the solution temperature, while $\sigma$ forms from transformed $\gamma$ at the temperature of calculation. For alloys of this type, the CCT diagram is often of equal importance and it is possible to convert a TTT diagram to a CCT diagram using well-known additivity rules [31]. Figure 8 shows a calculated CCT diagram for alloy 706.

In the original paper presented to the Seven Springs meeting, concerned with thermodynamic calculations for Ni-based superalloys [2], the case of TCP stability in U720 and U720LI was examined. It was possible to show that the somewhat minor change in composition of U720 to U720LI would cause a sharp drop in $\sigma$ stability, consistent with the experimental results of Keefe et al. [32]. However at that time it was not possible to calculate the TTT diagram. This has now been achieved and Figure 9 shows the calculated results with the experimental observations of Keefe et al. [32]. The results match the different behaviour of the two alloys rather well.

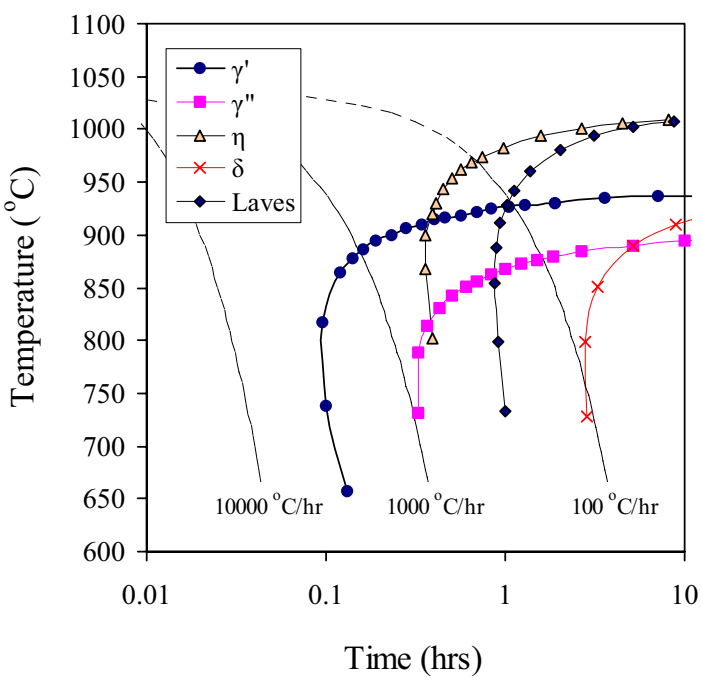

Figure 8. Calculated CCT diagram for alloy 706

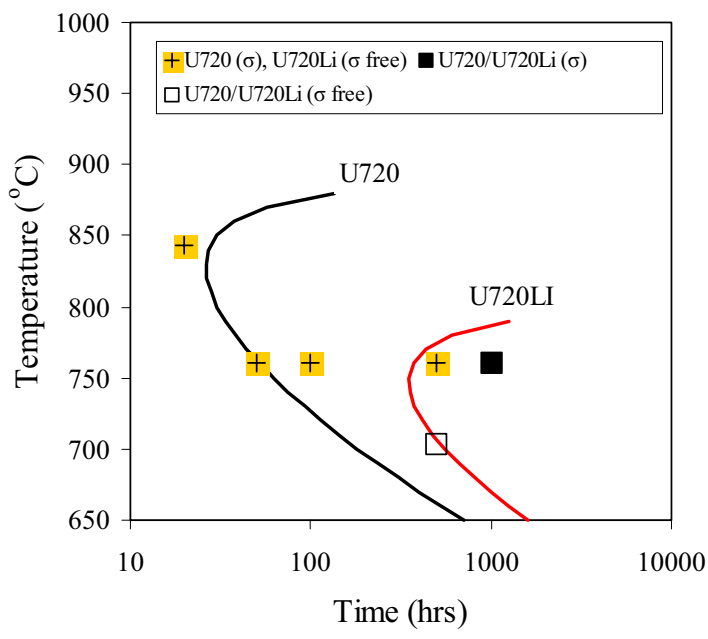

Figure 9. Calculated TTT diagrams for U720 and U720LI with experimental results of Keefe et al. [32] superimposed. 
Calculations have been extended to single crystal alloys. In this case there have been modifications to the thermodynamic database used in previous studies [3] and a better representation of the temperature range of formation of TCP phases in Recontaining alloys has been achieved. For single crystal alloys the number of potential nucleation sites has been taken as being considerably lower than that for a "normal" superalloy where the formation of TCP phases often occurs at grain boundary sites, which are absent in the single crystal alloy.

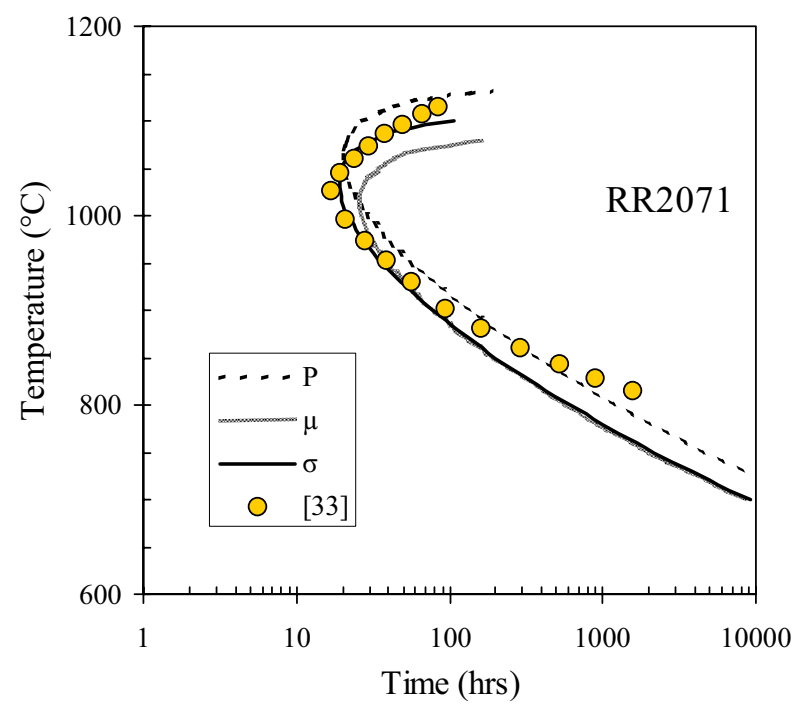

Figure 10. Calculated TTT diagram for the single crystal alloy RR2071 with experimental results of Rae at al. [33] superimposed

Figure 10 shows the results that can now be achieved for TTT calculations of such alloys. The alloy RR2071 is a good example to use as it exhibits the formation the three TCP phases, $\sigma, \mathrm{P}$ and $\mu$ [33]. The calculations show clearly the close competition in stability. The fast formation of $\sigma$ which is either metastable or the minor phase in the alloy is also interesting as such fast formation of $\sigma$ was noted by Rae et al. [33], where it was often seen as a precursor to the formation of the more stable phases.

\section{Coarsening of $\gamma^{\prime}$ and $\gamma^{\prime \prime}$.}

An important feature of Ni-based superalloys is coarsening of $\gamma^{\prime}$ and $\gamma^{\prime \prime}$ at high temperatures, both for processing and service life. Recently, Li et al. [34] have shown how a combination of CALPHAD calculations and existing theory of Ostwald ripening $[35,36,37]$ can be used to calculate coarsening rates of Ni-based superalloys to a high level of accuracy. The CALPHAD calculations provides critical information concerning the composition of $\gamma^{\prime}$ and $\gamma^{\prime \prime}$ and allows the calculation of the $\gamma / \gamma^{\prime}$ and $\gamma / \gamma^{\prime \prime}$ interfacial energy $(\sigma)$ for use in the relevant kinetic equation shown below.

$$
\bar{r}_{(t)}^{3}-\bar{r}_{o}^{3}=\frac{8 D \sigma N_{\alpha}\left(1-N_{\alpha}\right) V_{m}}{9 \varepsilon_{\alpha}\left(N_{\beta}-N_{\alpha}\right)^{2} R T} t
$$

where $\bar{r}_{0}$ is the mean radius at time $t=0, D$ is the diffusion coefficient, $N_{\alpha}$ and $N_{\beta}$ are the mole fractions of solute in the matrix and particle respectively, $V_{m}$ is the molar volume of $\gamma^{\prime}, \varepsilon_{\alpha}$ is the Darken factor, $R$ is the gas constant and $T$ is the temperature of coarsening. All of the required input can be readily calculated using JMatPro and Figure 11 shows the comparison [34] between experimentally observed and calculated growth rates of $\gamma^{\prime}$ in numerous commercial alloys and binary $\mathrm{Ni}-\mathrm{Al}$ alloys over a wide range of temperatures.

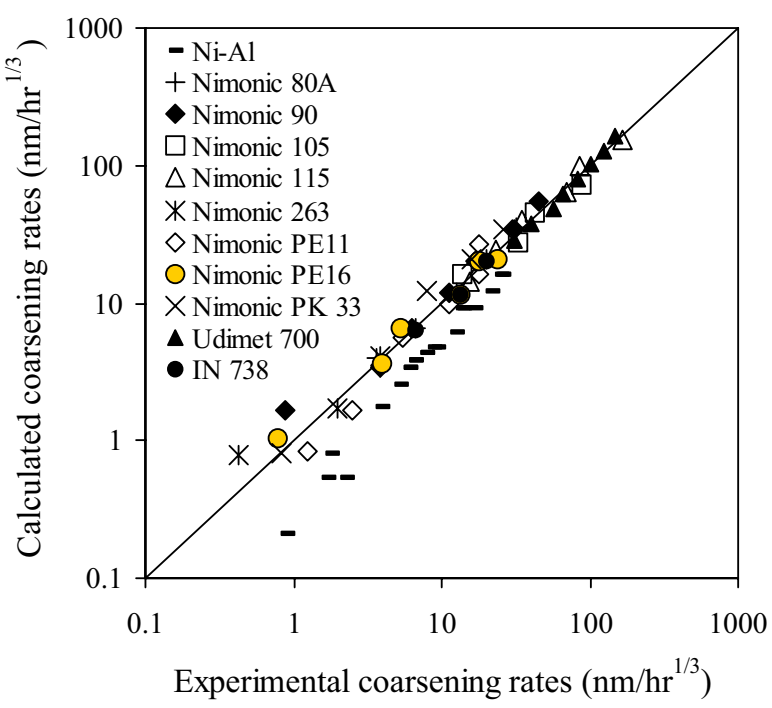

Figure 11. Comparison between calculated and experimentally observed $\gamma^{\prime}$ coarsening rate coefficients for Ni-based superalloys and Ni-Al binary alloys. (see Li et al.

[34] for references to experiment values).

The agreement is quite startling, with the only significant deviation between calculation and experiment being for binary $\mathrm{Ni}-\mathrm{Al}$ alloys at low temperatures. This can be directly correlated to their larger lattice $\gamma / \gamma^{\prime}$ misfit $(\delta)$ in comparison to those found in commercial alloys. Analysis by Li et al. [34] shows that as long as $\delta$ remains less than $0.4 \%$, which is the more usual case for $\mathrm{Ni}$-based superalloys, the calculations will provide high quality predictions.

The approach used for $\gamma^{\prime}$ coarsening has been directly applied to the case of $\gamma^{\prime \prime}$. In this case $\gamma^{\prime \prime}$ is also an ordered superstructure of the $\gamma$ phase, but possesses a body centred tetragonal structure $[38,39]$. The calculated coarsening rate at $750^{\circ} \mathrm{C}$ along the minor axes of $\gamma^{\prime \prime}$ in alloy $718\left(3.8 \mathrm{~nm} \mathrm{hr}^{-1 / 3}\right)$ is quite well matched to that experimentally measured $\left(2 \mathrm{~nm} \mathrm{hr}^{-1 / 3}\right)$ [40]. However, there is a substantially different coarsening rate measured along the major axis $\left(16 \mathrm{~nm} \mathrm{hr}^{-1 / 3}\right)$ where there is significant lattice mismatch, $\sim 3 \%$ [41]. This is consistent with the observation of increased coarsening rates of $\gamma^{\prime}$ in binary Ni-Al alloys with high lattice mismatch [34]. The increased rate has been taken into account empirically and at an appropriate ratio to the minor axes.

\section{Calculation of $\gamma^{\prime}$ and $\gamma^{\prime \prime}$ Strengthening}

The ability to make mechanical property calculations has been a feature of JMatPro since its inception. Solid solution strengthened alloys have been modelled using using the standard Hall-Petch equation [42]:

$$
\sigma_{y}=\sigma_{o}+k d^{-\frac{1}{2}}
$$


where $\sigma_{y}$ is the yield or proof stress, $\sigma_{o}$ is the intrinsic flow stress, $k$ is the Hall-Petch coefficient and $d$ is the grain size. Two types of databases for solid solution hardening have been created; one for intrinsic flow stress and the other for Hall-Petch coefficients. Both are similar in format to those used for physical properties and all that is required for a calculation is the composition of the $\gamma$ phase and the grain size. Good agreement with strengths of solid solution Ni-based alloys is found [10].

In Ni-based superalloys, strengthened by ordered $\gamma^{\prime}$ precipitates, dislocations typically travel in pairs because the passage of a pair of matrix dislocations through a $\gamma^{\prime}$ particle restores perfect order on the $\{111\}$ slip plane. When the particle is small, the yield (or proof) stress is determined by the stress that is necessary to move weakly coupled dislocation pairs. In this case, the first dislocation bows out and the second dislocation remains straight. Following Brown and Ham [43] the yield stress $\left(Y S_{l}\right)$ can be derived as

$$
Y S_{1}=Y S_{0}+M \frac{\gamma_{A P B}}{2 b}\left[\Phi\left(\frac{\gamma_{A P B} f d}{\tau}\right)^{\frac{1}{2}}-f\right]
$$

where $Y S_{0}$ is the yield (proof) stress due to solution hardening, $M$ is the Taylor factor [44] that relates the proof stress in polycrystalline material and critical shear stress (CRSS) in single crystal specimens $(\approx 3$ for FCC materials $[44]), \gamma_{A P B}$ is the APB energy in the $\{111\}$ plane, $b$ is the burgers vector of dislocation, $d$ is the particle diameter, $f$ is the volume fraction of $\gamma^{\prime}$ precipitates, $\tau$ is the line tension of the dislocation and $\Phi$ is a numerical factor depending on the morphology of the particles, which for spherical particles equals to 0.72 .

When the particles become large, the coupling of the dislocations can become particularly strong because both dislocations may reside in the same particle. Hüther and Reppich [45] have analysed this situation for spherical ordered precipitates and have derived a formula in which the yield stress (CRSS in original paper) decreases with increasing particle size according to:

$$
Y S_{2}=Y S_{0}+1.72 M \frac{\tau \omega f^{\frac{1}{2}}}{2 b d}\left[1.28 \frac{\gamma_{A P B} d}{\omega \tau}-1\right]^{\frac{1}{2}}
$$

The parameter $\omega$ accounts for the repulsion of the dislocations within the precipitates, and is essentially an empirically adjustable parameter. For any given particle size, $d$, the yield stress is governed by the lower of the two values $\mathrm{YS}_{1}$ and $\mathrm{YS}_{2}$ because dislocations will tend to move by whichever of the two mechanisms provides the least resistance to glide.

Most of the input into equations 4 and 5 can be calculated through an equilibrium thermodynamic calculation combined with assessed databases for moduli and solid solution strengthening. However, the most critical factor was found to be the APB energy, which is obtained from a thermodynamic calculation route as described previously [46]. Figure 12 shows the typical behaviour associated with hardening by $\gamma^{\prime}$ particles as a function of particle diameter; experimental data here are from Mitchell [47]. There is, initially, a steep rise in strength where the deformation mechanism is dominated by small particle effects. A peak is reached, after which the effect of dislocation coupling becomes more important and the strength then decreases with increasing size of $\gamma^{\prime}$ particles.

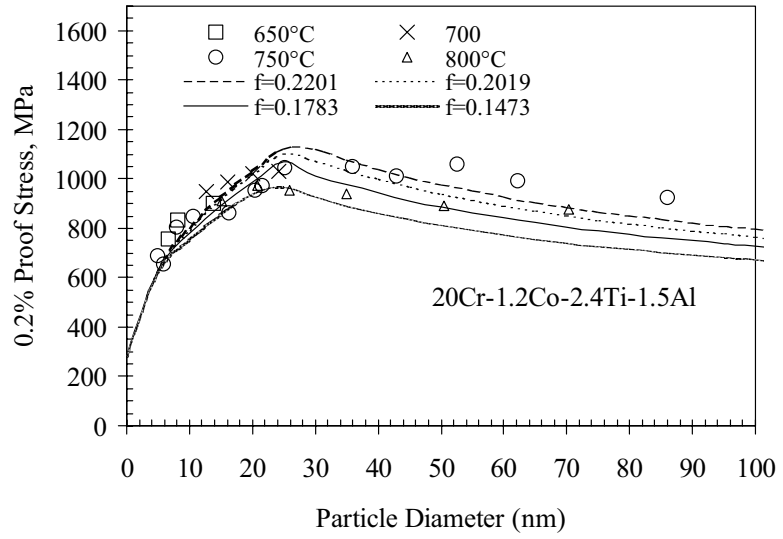

Figure 12. Comparison between calculated [10] and experimental [47] $0.2 \%$ Proof Stress as a function of $\gamma^{\prime}$ size and volume. $\gamma^{\prime}$ amounts are those calculated at the respective ageing temperature.

Calculations have also been made for a number of commercial superalloys where specific information on $\gamma^{\prime}$ size is available (Fig.12). Where size distributions are bi-modal or higher, the amount of $\gamma^{\prime}$ at the FHTT has been used for the calculation and the total strength obtained by a simple law of mixture summation of the strengthening effect of the various size distributions $[48,49]$.

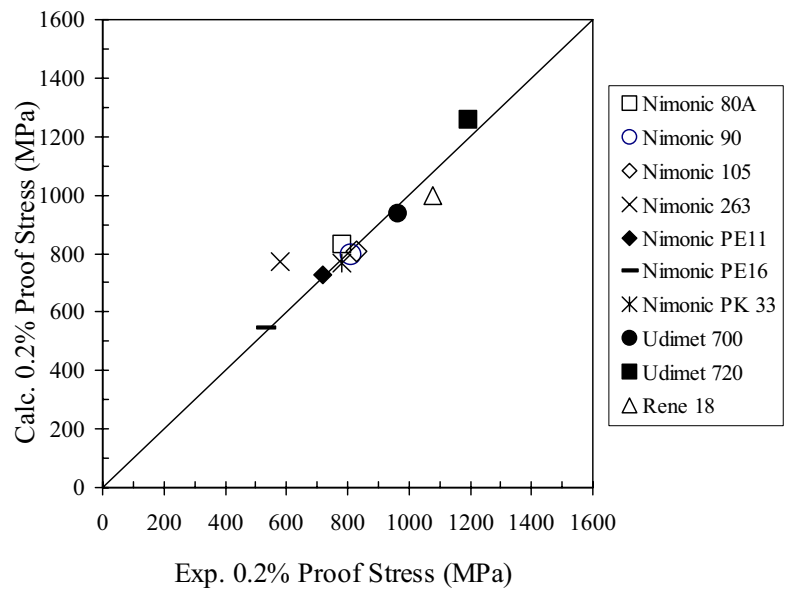

Figure 13. Comparison between calculated and experimental $0.2 \%$ proof stress of various commercial Ni-based superalloys. (see [10] for references to experiment values)

Alloys such as 625 and 718 are strengthened by the $\gamma^{\prime \prime}$ phase. It has a greater strengthening potential than $\gamma^{\prime}$, in the context that the same amount of $\gamma^{\prime \prime}$ will provide substantially more strength than $\gamma^{\prime}$. For example, $0.2 \%$ proof stress in 718 can reach levels associated with alloys such as U720, which may have twice the volume fraction of $\gamma^{\prime}$ present. This can be explained by the significant lattice mismatch of $\gamma^{\prime \prime}$ along its major axis, which provides a further strain hardening contribution. Equations have been used to take this into account after Oblak et al. [50], for small $\gamma^{\prime \prime}$ precipitates

$$
P S_{1}=1.7 G \varepsilon^{\frac{3}{2}}\left(\frac{r f}{b}\right)^{\frac{1}{2}}
$$


where $P S_{I}$ is the strength contribution from strain hardening from small particles, $\varepsilon$ is the lattice mismatch in the major axis, $r$ is the average radius of the particles in the major axis and $f$ is the volume fraction of the particle. For large $\gamma^{\prime \prime}$ precipitates, we use equation 7 below after Smallman [51].

$$
P S_{2}=0.7 G f^{\frac{1}{2}} \varepsilon^{\frac{1}{4}}\left(\frac{b}{r}\right)^{\frac{3}{4}}
$$

where $\mathrm{PS}_{2}$ is the strength contribution from strain hardening from large particles. For $\gamma^{\prime \prime}, \varepsilon$ is taken from Slama et al. [41]. The total particle strengthening contribution is considered to be a summation of that from strain hardening and dislocation cutting mechanisms.

Based on the above method, calculations have been made for the room temperature strength of a 718 alloy based on a $\gamma$ grain size of $100 \mu \mathrm{m}$ and $\gamma^{\prime}$ and $\gamma^{\prime \prime}$ particle sizes of 15 and $25 \mathrm{~nm}$ respectively, after Chaturvedi and Han [52], which is consistent with other studies of 718 and variants [40,53]. $0.2 \%$ proof stress is calculated as $1223 \mathrm{MPa}$ in comparison to the range found in commercial 718 alloys of $1185-1365 \mathrm{MPa}$.

\section{Creep}

Solid solution and polycrystalline alloys

The present work [54] uses a formulation for the secondary creep rate [55] that features both a back stress function and takes the stacking fault energy $\left(\gamma_{\mathrm{SFE}}\right)$ explicitly into account [56]. This approach was selected as it contains parameters that have an identifiable physical basis and which can be calculated selfconsistently. The ruling equation is taken as

$$
\dot{\varepsilon}=A D_{e f f}\left(\frac{\gamma_{S F E}}{G b}\right)^{m}\left(\frac{\sigma-\sigma_{o}}{E}\right)^{n}
$$

Where $\dot{\varepsilon}$ is the secondary creep rate, $A$ is a materials dependent parameter, $D_{\text {eff }}$ is the effective diffusion coefficient, $\gamma_{S F E}$ is the stacking fault energy of the matrix at the temperature of creep, $b$ is the burgers vector, $\sigma$ is the applied stress, $\sigma_{0}$ is the "back stress", with $G$ and $E$ the shear and Young's modulus of $\gamma$ at the creep temperature respectively. The back stress $\sigma_{o}$, is calculated following the treatment of Lagneborg and Bergman [57], setting $\sigma_{o}=0.75 \sigma$ when $\sigma<4 \sigma_{p} / 3$, (where $\sigma_{p}$ is the critical back stress from strengthening due to precipitates) and $\sigma_{o}=\sigma_{p}$ when $\sigma>4 \sigma_{p} / 3$. The exponents $m$ and $n$ are given a range of values in the literature, and in the present approach have been given fixed values of $m=3$ and $\mathrm{n}=4$.

The work of Miodownik et al. [54] has been further extended to austenitic steels and a more extensive examination of Ni-based solid solution alloys has been undertaken [58]. $D_{\text {eff }}$ is considered to have a contribution from pipe diffusion $\left(D_{\text {pipe }}\right)$, after Evans and Knowles [59.60], as well as lattice diffusion $\left(D_{\text {latt }}\right)$. This becomes important at low temperatures and high stresses.

Almost all input parameters for eq. 8 can be obtained through JMatPro. For example, $G$ and $E$ are calculated from the physical property calculations, $\sigma_{0}$ is directly calculated from the strengthening contribution of $\gamma^{\prime}$ or $\gamma^{\prime \prime}$ [54], $\gamma_{S F E}$ at the creep temperature is calculated from the Gibbs energy difference between $f c c$ and $h c p$ structures [61], and $D_{\text {eff }}$ is calculated from the

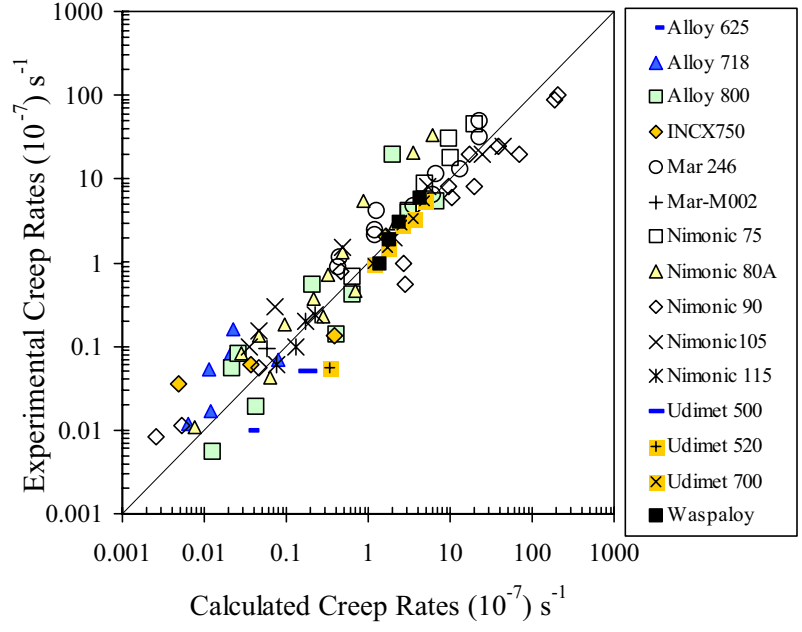

Figure 14. Comparison between calculated and experimental secondary creep rates for commercial solid solution and polycrystalline Ni-based superalloys. See [54] for references to original experiments

diffusion database. This leaves $A$ as the only adjustable parameter, which is taken here as being temperature dependent.

Figure 14 shows a comparison between calculated and measured secondary creep rates of a variety of Ni-based superalloys. As rupture strength is an alternative design criterion in many practical cases, the calculation procedure has been extended [54] to include this property by using an inverse relationship between stress rupture life and secondary creep rate $[62,63]$, such that

$$
t_{r}=\alpha \dot{\varepsilon}^{\beta}
$$

where $t_{r}$ is the time to rupture while $\alpha$ and $\beta$ are evaluated empirically. Combining eqs. 8 and 9 we have calculated $1000 \mathrm{hr}$ rupture strengths for a wide range of wrought Ni-based superalloys and compared with experimentally reported values [64] (Figure 15).

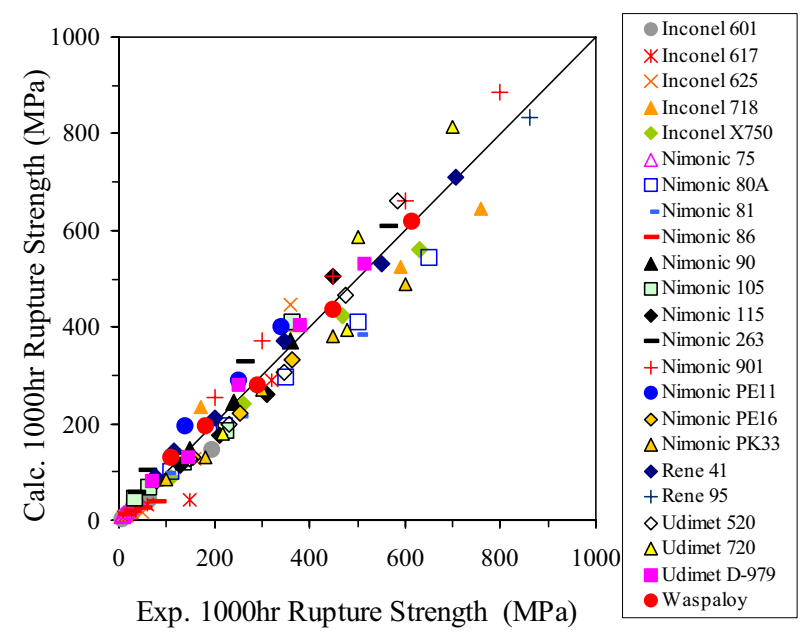

Figure 15. Comparison between experimental [64] and calculated $1000 \mathrm{hr}$ rupture strengths for various wrought Ni-based superalloys 
Previous calculations of $1000 \mathrm{hr}$ rupture strength [54] concentrated on results at $760^{\circ} \mathrm{C}$, or just above. Comparison is now made against a much wider range of alloys including higher temperatures. This was initially considered problematical because, at higher temperatures, particle coarsening could potentially cause a large decrease in back stress and, hence, an increased secondary creep rate. However, examination of calculated results, which take into account coarsening, shows in almost all cases the high temperature results would not change in Figure 15, because $\sigma<4 \sigma_{p} / 3$ and, therefore, creep would occur in the range where the back stress is proportional to the applied stress, i.e. $\sigma_{o}=0.75 \sigma$.

\section{$\underline{\text { Single Crystal Alloys }}$}

Modelling the creep of single crystal alloys is additionally complicated by crystal anisotropy and microstructural changes in $\gamma^{\prime}$ at high temperatures. As part of on-going work, anisotropy is being considered for single crystal alloys and, more generally, for texture effects in highly worked wrought alloys. In the meantime, we have applied equations 8 and 9 to single crystal alloys, but have assessed different values for the various constants.

Comparison between experimental $[65,66,67,68,69,70,71,72,73$, $74,75]$ rupture life for alloys including $1^{\text {st }}$ through $4^{\text {th }}$ generation types and calculated results is shown in Figure 16 for alloys with (001) orientations assuming a $\gamma^{\prime}$ particle size of $500 \mathrm{~nm}$ to calculate $\sigma_{p}$. It is noted that $\gamma^{\prime}$ strengthening is sufficiently large such that rupture would be controlled by creep in the range where the back stress is proportional to the applied stress, i.e. $\sigma_{o}=0.75 \sigma$.

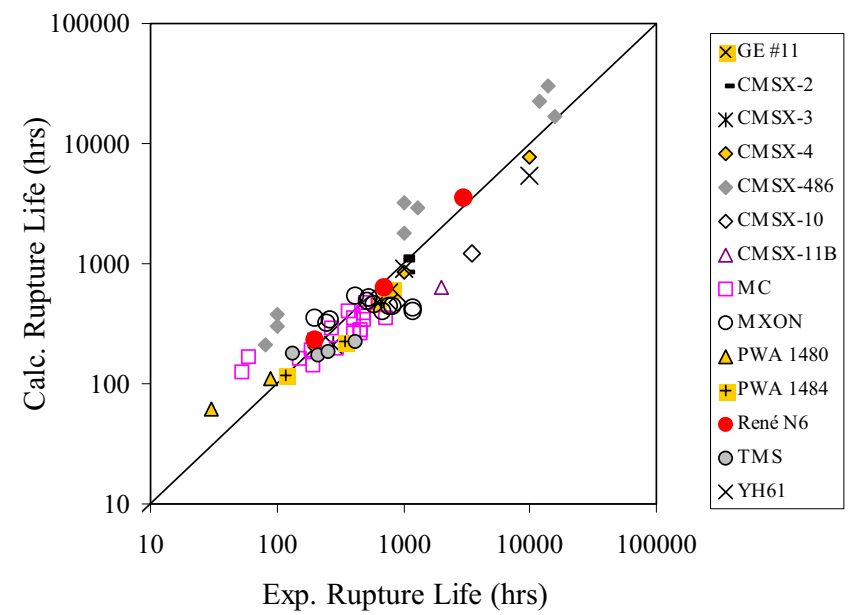

Figure 16. Comparison between experimental and calculated rupture life for various single crystal superalloys

As yet, the effect of crystal anisotropy on $G$ and $E$ has not been considered. This should be considered within a stringent use of eq.8. However, it is noted that both $G$ and $E$ in the (001) direction will be proportional to isotropic values. If this proportionality is fairly constant, which is not an unreasonable assumption for single crystal alloys because compositions and microstructures tend to be rather similar, the effect of anisotropy will be subsumed in the empirical evaluation of $A$. That we have achieved such good results, suggests that this is the case. In future work, the effect of $\gamma / \gamma^{\prime}$ lattice mismatch on creep will be explicitly modelled so as to account for effects as observed experimentally by Zhang et al. [74]. However, we note that the overall accuracy of the current calculations suggests that mismatch effects may not be a dominant feature of creep.

\section{High Temperature Tensile Properties}

Examination of the yield/proof stress as a function of temperature, $\sigma(T)$, for many austenitic steels and Ni-based solid solution alloys shows a clear correlation between the rate of decrease in $\sigma(T)$ with increasing temperature and the room temperature $0.2 \%$ proof stress $\left(\sigma_{R T}\right)$. The decay is well matched using an exponential form of the following type

$$
\sigma(T)=a+\beta \exp \left(\frac{-Q}{R T}\right)
$$

where $\alpha$ and $\beta$ are constants directly related to $\sigma_{R T}$ and the value of $Q$, which is determined empirically through regression analysis based on the data of a wide range of austenitic steels and nickelbased solid solution alloys.

For the case of $\gamma^{\prime}$ and $\gamma^{\prime \prime}$ hardened alloys, we have considered the strength contribution as described earlier. It is well established that the strength of $\gamma^{\prime}$ increases with increasing temperature [66] due to complex dislocation interaction. However, there is no direct input that can be used in eqs. 3 and 4 to take such an effect into account. To provide for an increase in $\gamma^{\prime}$ strength, we have taken the room temperature APB energy and given it a temperature dependence. Although this has no physical basis it does allow for the strengthening contribution of $\gamma^{\prime}$ to increase using a parameter that itself is closely related to dislocation behaviour. The temperature dependence is taken as a constant and has been evaluated based on the known behaviour of $\gamma^{\prime}$ hardened alloys.

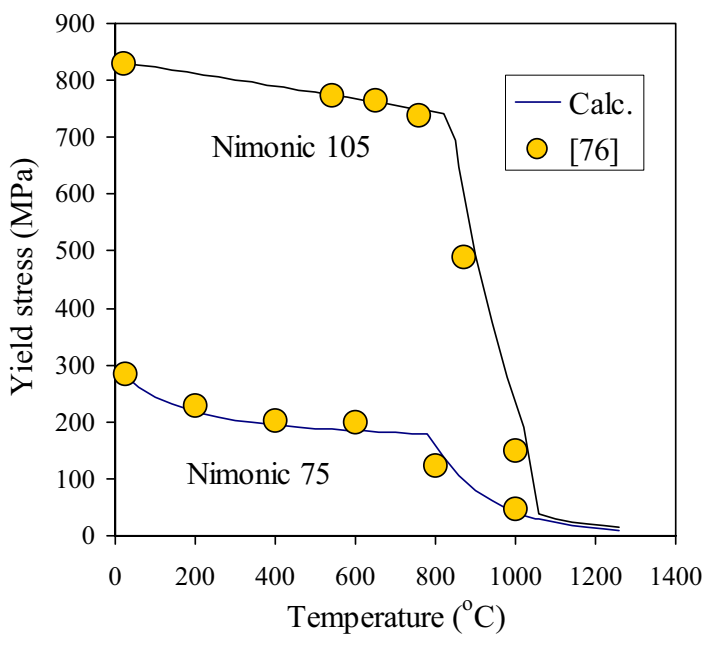

Figure 17. Comparison between experimental [76] and calculated yield stress for Nimonic 75 and 105 as a function of temperature.

As the temperature is raised to high levels the alloy will yield via creep when the strain rate of the mechanical test is equal to or slower than the creep rate at the testing temperature. Figure 17 shows the comparison between experimental [76] and calculated yield stress vs. temperature for two alloys, one a solid solution alloy (Nimonic 75) the other hardened by $\gamma^{\prime}$ precipitates 
(Nimonic 105). For Nimonic 105, in the creep controlled region, the alloy is weakened by the gradual removal of $\gamma^{\prime}$ to the point that, above its $\gamma^{\prime}$ of $1025^{\circ} \mathrm{C}$, it becomes fully $\gamma$.

The calculation procedure for solid solution alloys is simple as there is no significant phase change. However, for the case of $\gamma^{\prime}$ and $\gamma^{\prime \prime}$ hardened alloys the dissolution of $\gamma^{\prime}$ and $\gamma^{\prime \prime}$ must be considered. This has been dealt with in the same way as for the physical properties. Below the final heat treatment temperature, the $\gamma^{\prime}$ and $\gamma^{\prime \prime}$ amounts (and distribution) are taken to be kinetically "frozen in". Above this temperature dissolution to their equilibrium amount is allowed. The total number of $\gamma^{\prime}$ and $\gamma^{\prime \prime}$ particles is kept constant, which means that they shrink in size with increasing temperature.

There are two ways to make the calculation for $\gamma^{\prime}$ and $\gamma^{\prime \prime}$ hardened alloys. (i) The size and distribution of particles after final heat treatment is directly input. (ii) If such detail is not known the experimental $0.2 \%$ proof stress can be input and a single modal $\gamma^{\prime}$ and/or $\gamma^{\prime \prime}$ particle size is back calculated to provide the requisite value for $\sigma_{R T}$. Figure 18 shows a comparison between calculated and experimental [64] yield stress for a variety of alloys from RT to high temperatures, in which case we have used the measured $\sigma_{R T}$ as input for the calculation. It can be seen that agreement is very good and the reduction in strength as a function of temperature well matched.

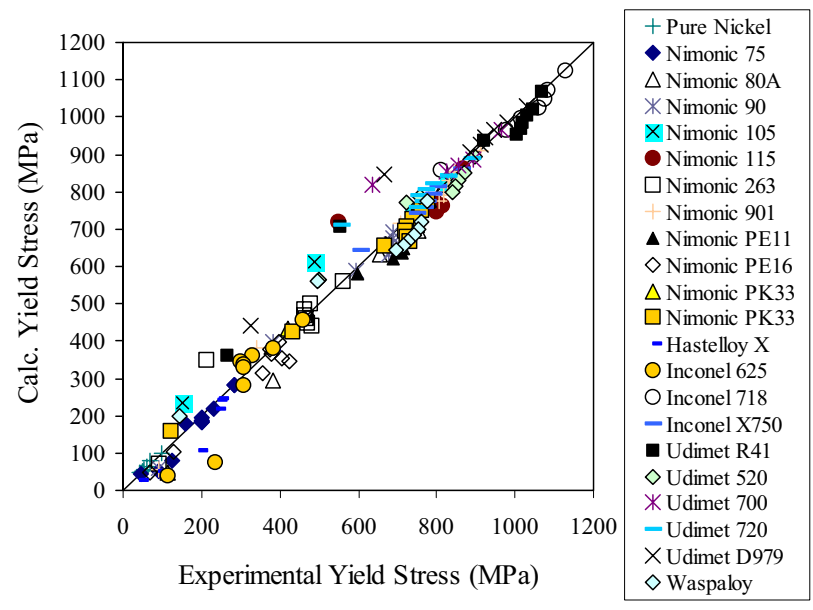

Figure 18. Comparison between experimental [64] and calculated yield stress at for various wrought superalloys and pure $\mathrm{Ni}$ between $\mathrm{RT}$ and $1000^{\circ} \mathrm{C}$.

\section{Summary}

This paper has described the technical background behind the development of a new computer programme, JMatPro, which calculates the materials properties and behaviour of complex multi-component Ni-based superalloys to a high level of accuracy. The new programme emphasises calculation methods that are based on sound physical principles rather than purely statistical methods, hence the shortcomings of methods such as regression analysis are overcome.

The inclusion of microstructurally sensitive parameters means that it is possible to make the link with materials models that are currently being developed for prediction of microstructure. Such links will accelerate the development of a true virtual capability for design and optimisation of casting processes and thermomechanical heat treatment schedules for new alloys as well as existing ones.

The use of physically based models also means that the true interrelationship between properties has been developed for complex situations such as in the modelling of creep and precipitation hardening. A key factor in the success of the approach has been the extensive validation of calculated results against experiment.

\section{References}

1. N. Saunders and A.P. Miodownik, CALPHAD Calculation of Phase Diagrams, Pergamon Materials Series vol.1, ed. R.W. Cahn, (Oxford: Elsevier Science, 1998).

2. N. Saunders, Superalloys 1996, eds. R. Kissinger et al. (Warrendale, PA: TMS, 1996), 115

3. N. Saunders, M.G. Fahrmann and C.J. Small, Superalloys 2000, eds. K.A. Green et al. (Warrendale, PA: TMS, 2000), 803.

4. C.J.Small and N.Saunders, MRS Bulletin, 24, (1999), 22.

5. M.G. Fahrmann and G.D. Smith, Advanced Technologies for Superalloy Affordability, eds. K.-M. Chang et al. (Warrendale, PA: TMS, 2000), 63.

6. B.A. Boutwell, R.G. Thompson, N. Saunders, S.K. Mannan, and J.J. deBarbadillo, Superalloys 718, 625, 706 and Various Derivatives, ed. E.A. Loria, (Warrendale, PA: TMS, 1996), 99

7. M.L. Gambone, S.B. Shendye, P. Andrews, W. Chen, M.N. Gungo, J.J. Valencia and M.L. Tim, Superalloys 2000, eds. K.A. Green et al. (Warrendale, PA: TMS, 2000), 161.

8. M.S.A. Karunarate, D.C. Cox, P. Carter and R.C. Reed, Superalloys 2000, eds. K.A. Green, T.M. Pollock and R.D. Kissinger, (Warrendale, PA: TMS, 2000), 263.

9. U. Grafe, D. Ma, A. Engstrom and S.G. Fries, Modeling of Casting, Welding and Advanced Solidification Processes VIII, eds. B.G. Thomas and C. Beckermann (Warrendale, PA: TMS, 1998), 227.

10. N. Saunders, X. Li, A.P. Miodownik and J-Ph. Schillé, Materials Design Approaches and Experiences, eds. J.-C. Zhao et al., (Warrendale, PA:TMS, 2001), 185.

11. N. Saunders, Z. Guo, X. Li, A.P. Miodownik and J-Ph. Schillé, JOM, 55(12) (2003), 60.

12. Z. Fan, P. Tsakiropoulos and A.P. Miodownik, J. Mat. Sci., 29 (1994) p.141.

13. Z. Fan, Phil. Mag. A, 73 (1996), p.1663.

14. A.P. Miodownik, N. Saunders and J.-P. Schillé, unpublished research.

15. Adv. Mater. Proc., 156 (6), (1999), 80.

16. I.B. Fieldhouse and J.I. Lang, U.S. Air Force Report, WADD-TR-69-904, 1961.

17. H. Leggett, J.L. Cook, D.E. Schwab and C.T. Powers, U.S. Air Force Report, AFML-TR-65-147, 1965.

18. B.L. Rhodes, C.E. Moeller, V. Hopkins and T.I. Marx, $A d v$. Cryogenic Engineering, 8 (1963), 278.

19. A. Royer, P. Bastie and D. Bellet, Phil. Mag. A, 72, (1995), 669.

20. W.J. Boettinger, U.R. Kattner, S.R. Coriell, Y.A. Chang and B.A Mueller, Modeling of Casting, Welding and Advanced Solidification Processes, VII, eds. M. Cross et al. (Warrendale, PA: TMS, 1995), p.649.

21. N. Saunders, Solidification Processing 1997, eds. J. Beech and H. Jones, (Sheffield: Univ.Sheffield, 1997), 362. 
22. N. Saunders, X. Li. A.P. Miodownik and J.-Ph. Schillé, Modelling of Casting, Welding and Advanced Solidification Processes $X$, eds. D. Stefanescu et al., (Warrendale, PA: TMS, 2003), 669.

23. N. Saunders, X. Li. A.P. Miodownik and J.-Ph. Schillé, Light Metals 2003, ed. P. Crepeau, (Warrendale, PA: TMS, 2003), 999.

24. N. Saunders, X. Li. A.P. Miodownik and J.-Ph. Schille, Magnesium Technology 2003, ed. H. I. Kaplan, (Warrendale, PA: TMS, 2003), p.135

25. N. Saunders, X. Li. A.P. Miodownik and J.-Ph. Schillé, Proc. Conf. Liquid Metal Processing 2003, Nancy, France, Sept.21-24, 2003, 253.

26. N. Saunders, X. Li. A.P. Miodownik and J.-Ph. Schille, to be published in Ti-2003 Science and Technology, ed. G. Luetering, (Weinheim, Germany: Wiley-VCH, 2004)

27. P. Auburtin, S.L. Cockcroft, A. Mitchell and A.J. Schmalz, Superalloys 718, 625, 706 and Various Derivatives, ed. E.A. Loria, (Warrendale, PA: TMS, 1997), 47.

28. Data downloaded from Auburn University's Materials Processing Center website, June 2003. (Web address http://metalcasting.auburn.edu/data/data.html)

29. X. Li, A.P. Miodownik and N. Saunders, Mater. Sci. Tech., $18,(2002), 861$.

30. A. Oradei-Basile and J.F. Radavich, Superalloys 718, 625 and Various Derivatives, ed. E.A. Loria, (Warrendale, PA: TMS, 1991), 325

31. J. S. Kirkaldy, Scand. J. Metall., 20 (1991), 50.

32. P.W. Keefe, S.O. Mancuso and G.E. Maurer, Superalloys 1992, eds. S.D. Antolovich et al., (Warrendale PA: TMS, 1992), 487.

33. C.M.F. Rae, M.S.A. Karunaratne, C.J. Small, R.W. Broomfield, C.N. Jones and R.C. Reed, Superalloys 2000, eds. K.A. Green et al., (Warrendale, PA: TMS, 2000), 767.

34. X. Li, N. Saunders and A.P. Miodownik, Metall.Mater.Trans.A, 33A (2002), p.3367.

35. I.M. Lifshitz and V.V. Slyozov, J. Phys. Chem. Solids, 19 (1961), 35 .

36. C. Wagner, Z. Elektrochem, 65 (1961), 581.

37. H.A. Calderon, P.W. Voorhees, J.L. Murray and G. Gkostorz, Acta Metall., 42 (1994), 991.

38. I. Kirman and D.H. Warrington, J. Iron Steel Inst., 205 (1969), 1264.

39. D.F. Paulonis, J.M. Oblak and D.S. Duvall, Trans. ASM, 62 (1969), 611.

40. M. Sundararaman P. Mukhopadhyay and S. Banerjee, Metall. Trans. A, 23A (1992), 2015.

41. C. Slama, C. Servant and G. Cizeron, J. Mater. Res., 12 (1997), 2298.

42. E.O. Hall, Yield Point Phenomena in Metals and Alloys, (London: Macmillan, 1970), 38.

43. L.M. Brown and R.K. Ham, Strengthening Mechanisms in Crystals, (London: Applied Science, 1971).

44. J.W. Martin, Precipitation Hardening: $2^{\text {nd }}$ ed., (London:

Butterworth-Heinemann, 1988), 79.

45. W. Hüther and B. Reppich, Z. Metallkde., 69 (1978), 628.

46. A.P. Miodownik and N. Saunders, Applications of

Thermodynamics in the Synthesis and Processing of Materials, eds. P. Nash and B. Sundman, (Warrendale, PA: TMS, 1995), 91.

47. V.W.I. Mitchell, Z. Metallkde., 7 (1966), 586.

48. B. Reppich, W. Kühlein, G. Meyer, D. Puppel, M. Schulz and G. Schumann, Mater. Sci. Eng., 83 (1986), 45.
49. D.J. Chellman, A.J. Luévano and A.J. Ardell, Strength of Metals and Alloys, (London: Freund Publishing, 1991), 537.

50. J.M. Oblak, D.S. Duvall and D.F. Paulonis, Mat. Sci. Eng., 13 (1974), 51.

51. R.E. Smallman, Modern Physical Metallurgy, (London: Butterworths, 1985), 392.

52. M.C. Chaturvedi and Y. Han, Superalloy 718-Metallurgy and Applications, ed. E.A. Loria, (Warrendale, PA: TMS, 1989), 489.

53. E. Guo, F. Xu and E.A. Loria, Superalloys 718,625 and Various Derivatives, ed. E.A. Loria, (Warrendale, PA: TMS, 1991), 397.

54. A.P. Miodownik, X. Li, N. Saunders and J.-P. Schille, Parsons 2003: Engineering Issues in Turbine Machinery, Power Plant and Renewables, eds. A. Strang et al., (London: Inst.MMM, 2003), 779.

55. X.S. Xie, G.L.Chen, P.J. McHugh and J.K. Tien, Scripta Metall., 16 (1982), 483.

56. C.R. Barrett and O.D. Sherby, Trans. Met. Soc. AIME, 233 (1965), 1116.

57. R. Lagneborg and B. Bergman, Met. Science, 10 (1976), 20.

58. Z. Guo, A.P. Midownik, N. Saunders and J.-P. Schillé, work in progress.

59. H.E. Evans and G. Knowles, Acta Metall., 25 (1977), 963.

60. H.E. Evans and G. Knowles, Strength of Metals \& Alloys, eds. P. Haasen et al., (Oxford: Pergamon Press, 1979), 301.

61. A.P. Miodownik, CALPHAD, 2 (1978), 207.

62. F.C. Monkham and N.J.Grant, Proc.Amer.Soc.Test.Mater., 56 (1956), 593.

63. P.W. Davies and B. Wilshire, Structural Processes in Creep, ed. A.G. Quarrell (London: Iron \& Steel Inst., 1961), 34.

64. Special Metals Product Handbook of High-Peformance Alloys, Publication No. SMC-035, (Huntington, WV: Special Metals Corporation, 2001).

65. K.S. O'Hara, W.S. Walston, E.W. Ross and R. Darolia, General Electric Company, patent \#5482789, Jan. 91996

66. Superalloys II, eds. C.T. Sims et al., (New York: Wiley \& Sons, 1987).

67. T.M. Pollock and A.S. Argon., Superalloys 1988, eds. S. Reichman et al., (Warrendale, PA: TMS, 1988), 285.

68. G.L. Erickson, Superalloys 1996, eds. R. Kissinger et al., (Warrendale, PA: TMS, 1996), 45.

69. K. Harris and J.B.Wahl, Parsons 2003: Engineering Issues in Turbine Machinery, Power Plant and Renewables, eds. A. Strang et al., (London: Inst.MMM, 2003), 687

70. W.S. Walston, K.S. O'Hara, E.W. Ross, T.M. Pollock and W.H. Murphy, Superalloys 1996, eds. R. Kissinger et al., (Warrendale, PA: TMS, 1996), 27.

71. A.D. Cetel and D.N. Duhl, Superalloys 1988, eds. S. Reichman et al., (Warrendale, PA: TMS, 1988), 235.

72. P. Caron, Superalloys 2000, eds. K.A. Green et al (Warrendale, PA: TMS, 2000) 757.

73. T. Khan, P. Caron and C. Duret, Superalloys 1984, ed. M. Gell et al., (Warrendale, PA: Met.Soc.AIME., 1984), p145.

74. J.X. Zhang, T.Murakumo, H. Harada and Y. Koizumi, Scripta Mater., 48 (2003), 287.

75. H. Tamaki, A. Yoshinari, A. Okayama, S. Nakamura, K. Kageyama, K. Sato and T. Ohno, Superalloys 2000, eds. K.A. Green, T.M. Pollock and R.D. Kissinger (Warrendale, PA: TMS, 2000), 757.

76. W. Betteridge and J. Heslop, The NIMONIC Alloys and Other Ni-Base High Temperature Alloys: 2nd ed., (London: Edward Arnold Ltd, 1974) 